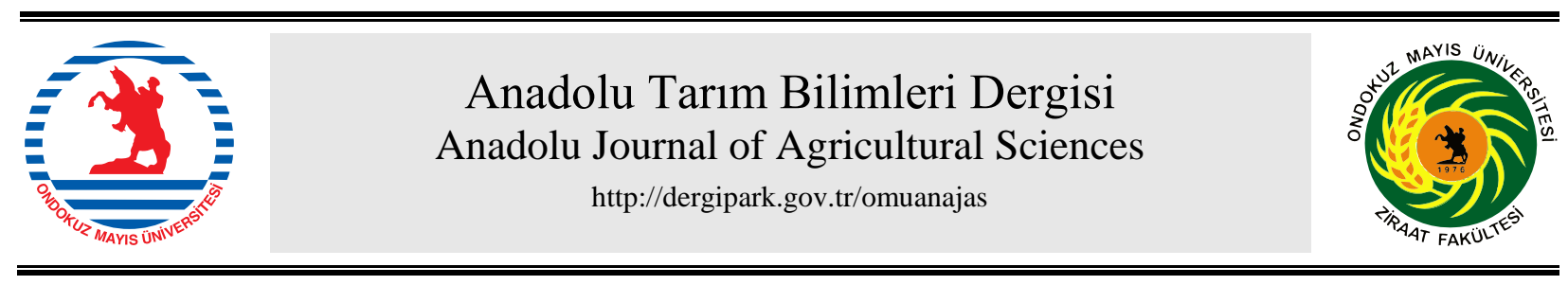

\title{
Araştırma/Research
}

Anadolu Tarım Bilim. Derg./Anadolu J Agr Sci, 34 (2019) ISSN: 1308-8750 (Print) 1308-8769 (Online) doi: 10.7161/omuanajas.491130

\section{Dactylorhiza romana (sebast.) soo. salep orkidelerinde dört yıllık gelişim sürecinin tanımlanması}

\author{
Ömer Çalışkan*, Dursun Kurt \\ Bitkisel ve hayvansal Üretim Bölümü, Bafra Meslek Yüksekokulu, Ondokuz Mayls Üniversitesi, Samsun \\ Tarla Bitkileri Bölümü, Ziraat Fakültesi, Gaziosmanpaşa Üniversitesi, Tokat
}

Geliş/Received 01.12.2018 Kabul/Accepted 06.05.2019

\begin{abstract}
ÖZET
Yumrulu orkideler, salep orkidesi olarak bilinir ve yüzyıllardır doğadan toplanıp tıbbi bitki olarak kullanılmaktadır. Vejetatif ya da generatif olarak üretim olanakları kısıtlı olduğu için nesli tehlike altında olan türlerdir. İn-vitro çalışmalar ile tohum çimlenmesi başarılmış ancak çimlenen bireylerin yıllar itibariyle gelişim durumu ile ilgili hiçbir kaynağa rastlanmamıştır. Bu çalışmada Dactylorhiza romana türünün doğada çimlenen tohumlarından gelişen filizler materyal olarak kullanılmıştır. Toplanan minik salep filizlerinin dört yıl süre ile gelişimleri izlenmiş ve her vejetasyon yılı sonunda bazı morfolojik özellikleri belirlenmiştir. Tohumun çimlenmesi ile gelişmeye başlayan bitkilerde ilk yıl bir adet yaprak ve ortalama 0.25 gramlık yumru oluşmuştur. $\mathrm{Bu}$ yumruların dikilmesi ile ikinci y1l bitkiler 3 yaprak ve 0.99 gram yumru üretmiştir. Üçüncü y1lda ilk kez çiçek oluştuğu görülmüştür. Çiçek üretme olgunluğu gösterinceye kadar geçen süreye yetişkinlik süresi adı verilmiş ve Dactylorhiza romana türünde yetişkinlik süresinin 3 yıl olduğu ortaya konulmuştur. Ancak bitkiler dördüncü yılda yeterli büyüklüğe ulaşmış ve ortalama 3.11 gramlık yumru üretebilmiştir.
\end{abstract}

Description of development period of Dactylorhiza romana (Sebast.) Soo. during four consecutive years

\section{ABSTRACT}

Tuberous orchids are known as salep orchids and have been collected from nature as medicinal plants for centuries. Propagation of the orchids via vegetative or reproductive parts has not yet been achieved, therefore they are endangered species. Seed germination was achieved by in-vitro studies, but there is no report on annual development status of the seed-derived individuals. In this study, sprouts from Dactylorhiza romana species germinating in nature were used as material. The four-year development of the small shoots was monitored. Some morphological characteristics were determined at the end of each year. In the first year, one leaf and tuber 0.25 gram in weight were formed. In the second year, individuals producing 3 leaf and 0.99 gram tuber did not bloom. Flowering was observed at first in the third year. The period until first flowering was described as adulthood stage and this period was observed as three years for Dactylorhiza romana. However, the plants reached enough size in the fourth year and were able to produce an average of 3.11 grams of tuber.

\section{Giriş}

Orchidaceae familyası, 25-30.000 civarında tür ile yeryüzünde en geniş çeşitliliğe sahip ikinci familyadır. Yeni bulunan ve melez türler ile bu sayı daha da artmaktadır (Özkoç, 1991; Arditti ve Ghani, 2000). Familya içinde terrestrial orkide olarak adlandırılan ve toprak altında yumru üreten türler salep orkidesi olarak bilinmektedir. Salep orkidelerinin yumruları yüzyıllardır tıbbi bitki olarak kullanılmaktadır (Baytop, 1994, 1999; Kasparek ve Grim, 1999; Isin, 2008). Günümüzde ise çoğunlukla maraş tipi dondurma yapımında ve sıcak 2011; Gorbani ve ark., 2014).
Anahtar Sözcükler:

Çiçek

Orkide

Salep

Verim

Yıllık gelişim

Yumru
Keywords:

Annual development

Flower

Orchids

Sahlep

Tuber

Yield

(C) OMU ANAJAS 2019 içecek olarak tüketilmektedir (Sezik, 2002; Hossain,

Orkideceae familyası içinde Dactylorhiza cinsinin farklı bir yeri vardır. Diğer tüm salep orkideleri oval şekilli yumru üretirken Dactylorhiza cinsi parmak şekilli yumrular üretmektedir. Geniş adaptasyon kabiliyeti sayesinde $0-2000 \mathrm{~m}$ rakımlar arasında görülebilmekte, Avrupa, Akdeniz ve Kuzey Afrika'dan Asya'ya kadar yayıldığı bildirilmektedir (Renz ve Taubenheim, 1984; Shipunov ve ark., 2004; Daşkın ve ark., 2007; Ernaz ve ark., 2012). Diğer türlerden bir diğer farkı ise yüksek glukomannan içeriğine sahip 
olmasıdır. Bu özelliği ile daha değerli bir salep orkidesi cinsidir (Farhoosh ve Riazi, 2007; Blinova ve Uotila 2012; Çalışkan 2018). Araştırma materyali olarak seçilen Dactylorhiza romana türü de iki parmaklı yumru oluşturan ve 1 lıman kuşakta yaygın görülen önemli bir salep orkidesi türüdür.

Orkidelerin çiçeklerinde, döllenmeden sonra gelişen ovaryum, kapsül şeklinde meyveyi oluşturmaktadır. İçerisinde mekik şekilli binlerce tohum bulunmaktadır. Tüm orkidelerin ortak özelliği hepsinde çok küçük, toz benzeri, mikroskopik tohumlara sahip olmalarıdır. Orkideler ailesini diğer tohumlu bitkilerden ayıran en önemli husus ise orkide tohumlarında besi doku olmayışıdır. Bitkiler âlemindeki bilinen en küçük tohumlar arasında yer almaktadır. Tohum uzunluğu 0.25-1.2 mm, genişliği 0.09-0.27 mm ve ağırlı̆ğ 0.3-14 mg kadardır. Tohumlarında endosperm bulunmadığı gibi embriyoları da nispeten az hücreden (40-50 adet) oluşmuştur. Tohum yapısındaki dikkate değer diğer bir

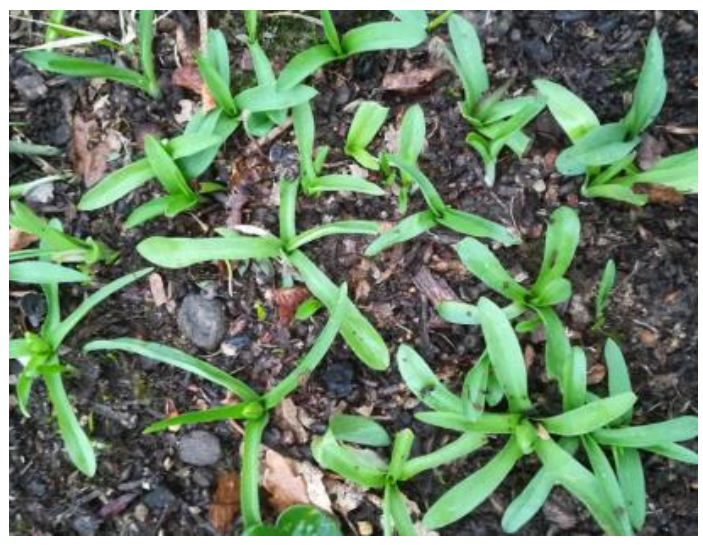

konu ise çimlenme sonrası kök, gövde, sürgün gibi bitki kısımlarını oluşturacak kısımların şekillenmemiş olmasıdır. $\mathrm{Bu}$ duruma morfolojik dormansi denilmektedir. Kısacası ilkel embriyolu ve besi dokusu olmayan tohumlardır (Arditti, 1967; Baskın ve Baskın, 1998; Çı̆̆ ve ark., 2018). Yetişkin bir salep orkidesi en az 8-10 adet tohum kapsülü ve bu kapsüller içinde onbinlerce tohum üretebilmektedir. Ancak toz zerreleri kadar küçük ve besi dokudan yoksun tohumların kendi kendilerine hayata tutunmaları, çimlenip filizlenmeleri imkânsızdır. Çimlenme aşamasında tohumlar farklı bir canlı organizmadan destek almadan gelişemezler. Çimlenme öncesinde az sayıdaki hücrelerde farklılaşma olması ve görev dağılımı yapılarak kök, sürgün gibi kısımları oluşturacak bölümlerin şekillenmesi gereklidir (Rasmussen, 1995; Sezik ve ark., 2007; Bektaş ve ark., 2013; Warghat ve ark., 2014).

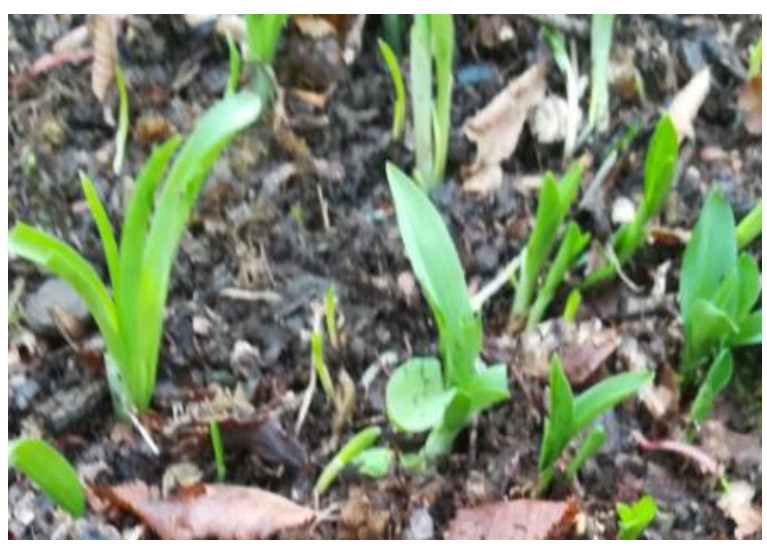

b

Şekil 1. Dactylorhiza romana türüne ait popülasyonun 20.02.15 tarihinde tespit edilen gelişim durumu, a: Orman içinde yayılış gösteren Dactylorhiza romana popülasyonu, b: Popülasyon içinde çimlenerek filizlenmiş yeni bireyler

İlkel tohumları nedeniyle orkidelerin etrafa saçtıkları sayılamayacak kadar çok tohumdan belki de milyonda biri çimlenme şansı yakalamaktadır. Çimlenebilen tohumların ise gelişimleri çok yavaştır ve uzun yıllar sürmektedir. Biyolojik özellikleri diğer bitkilerden oldukça farklı olan salep bitkisinin doğal koşullarda embriyolarının çimlenip bitkicik oluşturma süresi türler arasında farklılık göstermektedir. Çimlenen fidenin ilk yıl 1-2 küçük yaprak ile vejetasyon sürecini tamamladığı bilinmektedir. İlerleyen yıllarda bitkilerde büyüme devam etmekte ve çiçek oluşturma yeteneğine kavuşmaktadırlar. Tohumun çimlenmesinden çiçeklenme büyüklüğüne ulaşılıncaya kadar geçen sürece yetişkinlik süreci diyebiliriz. Çünkü sadece generatif olgunluğa ulaşabilen bireyler çiçek oluşturup tohum üretebilmektedir. $\mathrm{Bu}$ sürenin kaç yıl süreceği türlerin genetik özelliklerine bağlı olarak değişmektedir. Çünkü tohumların doku kültürü ortamında çimlendirilmesi ve devamında oluşan protokormlardan bitki geliştirilmesi, dünya genelinde başarılmış ancak elde edilen fidelerin gelişim süreçleri takip edilmemiştir. $\mathrm{Bu}$ konuda bilgi eksikliği oluşmuştur (Sezik, 1984; Çalışkan, 2018). Doku kültürü ile in vitro çalışmalar çoğunlukla tür bazında çimlendirme çalışmaları ile kısıtlı kalmaktadır. Burada doğal ortamlarda gözlem yapan bazı araştırıcıların tespitlerine yer verilebilir. Örneğin; salep orkidelerinde tohumdan üretim konulu çalışmalarında Tutar ve ark. (2013), çimlenen tohumların 3-4 yil sonra çiçeklenme büyüklüğüne ulaşabileceğini ifade etmişlerdir. Sezik (1984)'de çimlenen tohumlardan yaprak ve yumrunun uzun yıllar sonra meydana geldiğini bildirmiştir. Aynı araştırıcıya göre ortalama en kısa süre 2-4 yıldır. Ancak hangi salep orkidesi türünün kaç yılda yetişkinlik sürecini tamamladığına dair yeterli kaynak yoktur.

Yürütülen bu çalışma ile arazi gezilerinde, doğal ortamlarında çimlendikleri ve çıkış yaptıkları tespit edilen D. romana türü salep orkidesi türüne ait filizler toplanmıştır. Elde edilen bu filizlerin gelişimleri 4 yıl takip edilmiş ve yllar itibariyle büyüme gelişme 
durumları ortaya konulmak istenmiştir.

\section{Materyal ve Yöntem}

Samsun salep orkideleri çeşitliliğinin belirlenmesi amaciyla yapılan arazi gezilerinde özellikle orman kenarlarında, Dactylorhiza romana türünün yaygın olduğu görülmüştür. Çalışma materyali olan tür, Ondokuzmayıs ilçesi Dağköy mevkiinde tespit edilmiştir. 20 Şubat 2015 tarihinde yapılan saha gezisinde türün yayılış gösterdiği bölgede yetişkin bireylerin çevrelerinde tohumdan geliştiği anlaşılan yeni filizler gözlenmiştir.

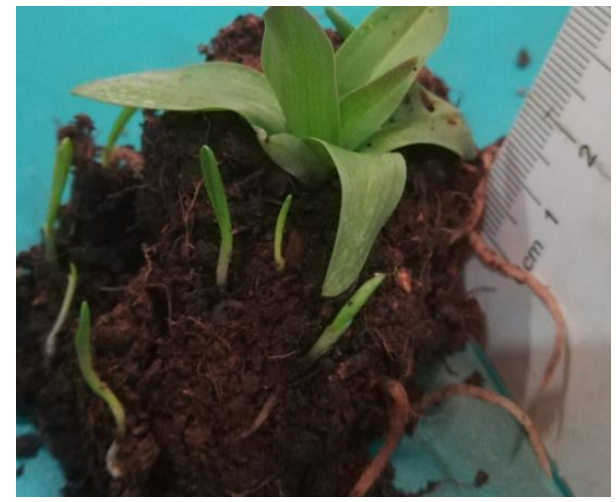

Şekil 2. Yetişkin bir Dactylorhiza romana bireyi etrafinda dökülen tohumlardan geliştiği anlaşılan filizler

Y1llar itibariyle bu yeni bireylerin gelişimlerini takip etmek ve yetişkinlik sürecini ortaya koymak amacıyla örnek materyal toplanmıştır. Deneme materyalinin toplandığ1 alanda, Dactylorhiza romana türüne ait popülasyonun 20 Şubat 2015 tarihinde ki gelişim durumu Şekil 1'de, yetişkin bir Dactylorhiza romana bitkisi ile etrafinda tohumdan büyüyen filizlerin görseli de Şekil 2'de görülmektedir. Şekil 2'de görülen filizlerden 30 adet filiz, yetişkin bireylerden ayrılarak kendi toprağı ile birlikte saksılara nakledilmiștir. Çalışma materyali olarak kullanılan bu 30 filizden 11 tanesi Şekil 3 'te verilmiştir.

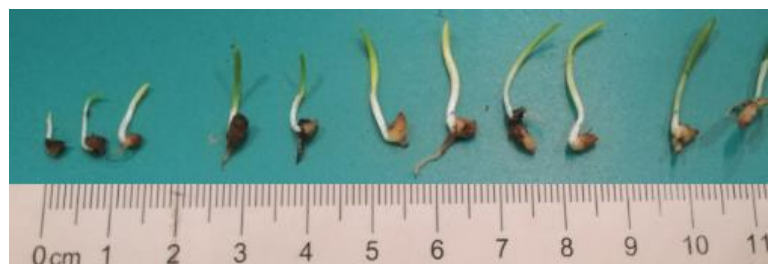

Şekil 3. Deneme materyali; çimlenme şansı yakalamış tohumların gelişmeye başlaması ile oluşan filizler (ilk gelişim durumunu gözlemlemek için toprakları temizlenmiştir).

Salep orkidelerinde çimlenmenin gerçekleştiği ilk yıl minik bir yumru üretilmektedir. Bu minik yumru, bir sonraki vejetasyon yılında, kendisinden daha büyük yeni bir yumru üreterek yetişme sezonunu tamamlamaktadır. $\mathrm{Bu}$ süreç yeni yumru belli bir büyüklüğe gelinceye kadar devam etmektedir. Eski yumru ise vejetasyon sonunda çürüyerek kaybolmaktadır. Dört vejetasyon yılının incelendiği bu çalışmada, fidelerin yıllık gelişim durumlarını özetlemek amaciyla her vejetasyon yılı sonunda bitki boyu, yaprak sayısı, yaprak boyu, yaprak eni, yumru boyu, yumru eni ve yumru ağırlığı ölçümleri alınmıştır.

\section{Bulgular ve Tartışma}

Tüm orkidelerde olduğu gibi salep orkideleri de hayatlarının ilk safhası olan çimlenme aşamasında dışarıdan, başka bir canlı grubunun yardımı ile beslenmek zorundadır. Salep tohumlarının çimlenmesine yardım eden ve gerekli besinleri sağlayan mikorhiza grubundan mantarlardır. İlk gelişim döneminde salep orkidesi tohumları funguslar ile ortak yaşama girmektedirler. Mikorhizal funguslar toprakta bulunan organik kalıntılardan sağladıkları besinleri orkide tohumuna vererek onu beslemekte ve büyümelerine yardımcı olmaktadır. Mikorhizal mantar ile tohum arasındaki bu ilişkiye simbiyotik yaşam adı verilmektedir (Rasmussen, 1995; Çağlayan ve ark., 1998; Jacobsone, 2008; Bektaş ve ark., 2013; Mehra, 2014). Şekil 3 incelendiğinde çimlenmiş ve sürgün çıkışı gerçekleşmiş olan ve yaprak oluşturan bireylerde kök sistemi olmadığ 1 görülmektedir. Bu durum tohumun mantarlar tarafından beslendiğini kanıtlayan yeni bir örnektir.

Diğer orkide türlerinde olduğu gibi Dactylorhiza romana salep orkidesinin tohumları çimlendikten sonra, gelişim süreçleri uzun yıllar devam etmektedir. Y1llık büyüme durumu ve çiçeklenme yılı hakkında hiçbir kaynağa rastlanmamıştır. Bilgi eksikliğinin giderilmesi amacıyla yürütülen bu çalışmada doğal ortamlarında çimlenmiş olan bireyler kullanılmıştır. Dört yıl takip edilen gelişim sürecinde, elde edilen morfolojik özelliklerin yanı sıra örnek bireyler her vejetasyon sonunda resimlenmiştir (Şekil 4). Bitkiler solmaya başladıklarında gelişimlerinin durduğu anlaşılmaktadır ve gerekli ölçümler bu aşamada yapılmıştır. Elde edilen morfolojik özellikler Çizelge 1'de görülmektedir.

Materyal olarak kullanılan 30 bitkicikte de, ilk y1l sadece bir adet yaprak gelişimi olmuştur (Şekil 4a). Ortalama yaprak eni $0.8 \mathrm{~cm}$, yaprak boyu ise $5.9 \mathrm{~cm}$ 'dir. İlk yıl üretilen yumrunun yaş ağırlığı sadece 0.25 gramdir. $\mathrm{Bu}$ minik yumrular yaz dönemini dormant olarak geçirmiş ve 5 Eylül 2015 tarihinde saksılara dikilmiştir. İkinci vejetasyon y1lı 21 Mayıs 2016 tarihinde tamamlanmıștır.

İkinci y1l vejetasyon döneminde bitkiler, 3 adet yaprak meydana getirmişlerdir. Vejetasyon sonunda ikinci yıl yumrularının ortalama ağırlığı 0.99 gr olarak ölçülmüştür. İlk iki yıl bitki boyu değerleri alınmamıştır. Zira bu yıllarda yaprak haricinde toprak üstü aksamı yoktur.

Üçüncü vejetasyon yılı performanslarını belirlemek amaciyla 1 Eylül 2016 tarihinde yumru dikimleri yapılmıştır. Denemeye alınan bireylerde 3. yılda 5-6 
adet çiçek üretildiği görülmüştür. Bilindiği gibi çiçek üretme olgunluğuna ulaşma süresi, yetişkinlik süreci olarak adlandırılmakta ve Dactylorhiza romana türünde yetişkinlik süreci 3 yıl olarak belirlenmiştir. Yaprak boy ve eni özelliklerinde ikinci yıla nazaran bir miktar artış olmuştur. Ancak en önemli artış yaprak sayısında gerçekleşmiş ve 6 adet yaprak oluştuğu tespit edilmiştir.
Üçüncü vejetasyon yllında çiçeklenen bitkiler ortalama $16.3 \mathrm{~cm}$ boya ulaşmış ve 2.3 gramlık taze yumru üretmişlerdir. Dördüncü vejetasyon dönemi kontrolleri için 7 Eylül 2017 tarihinde dikim yapılmıştır. Bitkilerin kütleleri üçüncü yıla nazaran daha da artmış ve bitki boyu $24.5 \mathrm{~cm}$ 'ye oluşan yeni yumruların ağırlığı ortalama 3.11 grama ulaşmışı ır (Çizelge 1).

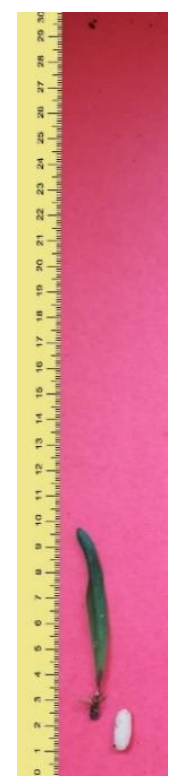

1. $\mathrm{y} 11$

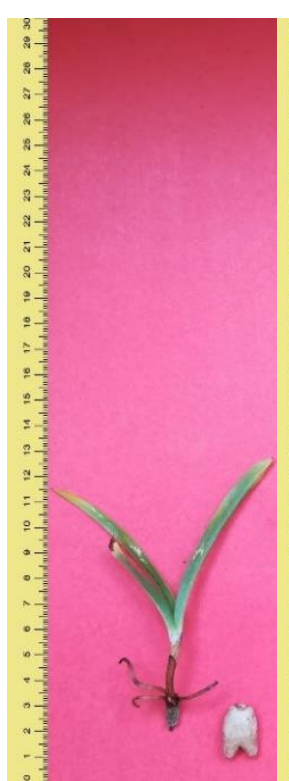

2. y1l

(21.05.16)

Sekil 4b

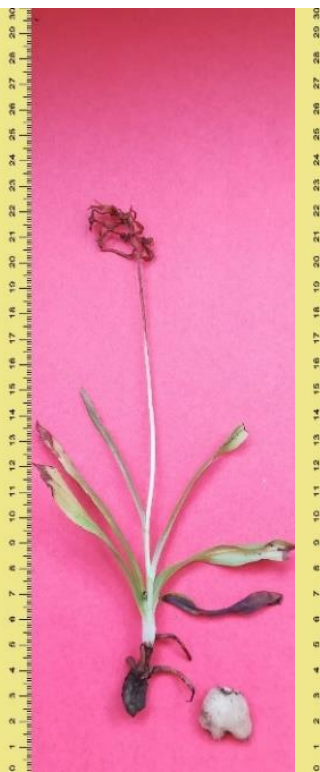

3. y1l

(20.05.17)

Sekil 4c

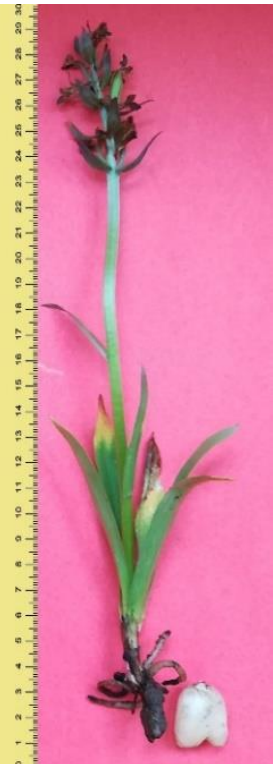

4. $\mathrm{y} 1 \mathrm{l}$

(18.05.18)

Sekil 4d

Şekil 4. Dactylorhiza romana bireyinin 4 ylllık gelişim durumu

Çizelge 1. Dactylorhiza romana bireyinin dört yıllık gelişim sürecine ait bazı morfolojik özellikleri

\begin{tabular}{cccccccc}
\hline Yillar & $\begin{array}{c}\text { Bitki boyu } \\
(\mathrm{cm})\end{array}$ & $\begin{array}{c}\text { Yaprak sayıs1 } \\
(\text { adet/bitki })\end{array}$ & $\begin{array}{c}\text { Yaprak boyu } \\
(\mathrm{cm})\end{array}$ & $\begin{array}{c}\text { Yaprak eni } \\
(\mathrm{cm})\end{array}$ & $\begin{array}{c}\text { Yumru boyu } \\
(\mathrm{mm})\end{array}$ & $\begin{array}{c}\text { Yumru eni } \\
(\mathrm{mm})\end{array}$ & $\begin{array}{c}\text { Yumru ağırlığ } \\
(\mathrm{gr})\end{array}$ \\
\hline 1. Y11 & - & 1 & 5.9 & 0.8 & 1.5 & 0.5 & 0.25 \\
2. Y11 & - & 3 & $5.8-7.8$ & $0.7-1.1$ & 1.7 & 1.2 & 0.99 \\
3. Y11 & 16.3 & 6 & $6.0-8.2$ & $0.6-1.2$ & 1.9 & 1.8 & 2.30 \\
4. Y11 & 24.5 & 8 & $6.9-9.1$ & $0.7-1.3$ & 2.4 & 2.0 & 3.11 \\
\hline
\end{tabular}

\section{Sonuç}

Tek bir salep orkidesinin onbinlerce hatta yüzbinlerce tohum ürettiği düşünüldüğünde salep tohumlarının yaşama şansının çok düşük olduğu anlaşılmaktadır. Tabiatta çimlenme şansı bulan tohumlar ise ilk yll minik bir bitki olarak gelişimini tamamlamaktadır. Dactylorhiza romana türünün gelişiminin takip edildiği bu çalışmada bitkilerin yeterli büyüklüğe 4 yılda ulaştıkları anlaşılmaktadır. Elde edilen bulgular tür için ilk kez ortaya konulmaktadır. Dikkat çeken bir husus da yumru büyüklügünün her geçen yıl, bir önceki yıla nazaran azda olsa artmasıdır. Genetik kapasiteleri elverdikçe, salep orkidelerinde yumrular belli bir büyüklüğe gelinceye kadar bu durum devam etmektedir. Ana yumru kendisinden biraz daha büyük yeni yumru üreterek hayatını tamamlamaktadır. Tüm salep orkidelerinde benzer durum söz konusudur (Çalışkan 2018). Bu çalışmada ilk yıl gelişen yumrular $(0.25 \mathrm{~g})$ dikildiğinde kendilerinden yaklaşık 4 kat büyük yumru oluşturdukları ve 0.99 gr. yumru ağırlığına ulaştıkları anlaşılmaktadır. $\mathrm{Bu}$ yumrular üçüncü vejetasyon yılı için dikildiğinde kendi ağırlıklarının 2.35 katında yumrular üretmiştir. Denemenin dördüncü yılında ise bir önceki yıla göre ana yumrular kendilerine oranla 1.35 kat fazla ağırlıkta yeni yumrular meydana getirmiştir. Görüldüğü gibi oransal olarak yumru iriliğinde ilk yıllarda hızlı bir artış, ilerleyen yıllarda ise artış hızında yavaşlama mevcuttur. Yumruların kaç yılda ve hangi koşullarda genetik kapasiteye ulaştığına dair herhangi bir çalışma mevcut değildir. Bunun tespitine yönelik, uzun yılları kapsayan çalışmalar 
yapılması eksikliğin giderilmesi için faydalı olacaktır. $\mathrm{Bu}$ çalışma neticesinde dünyada ilk kez Dactylorhiza romana türünün 4 vejetasyon yılında gelişim durumu ortaya konulmuştur.

\section{Kaynaklar}

Arditti, J., 1967. Factor affecting the germination of orchid seeds. Botanical Review, 33: 1-97. https://doi.org/10.1007/BF02858656

Arditti, J., Ghani, A.K., 2000. Numerical and physical properties of orchid seeds and their biyological implications. New Phytologist, 145: 367-421. https://doi.org/10.1046/j.1469-8137.2000.00587.x

Baskın, C.C., Baskın, J.M., 1998. Seeds. Ecology, biogeography, and evolution of dormancy and germination. Academic Press, XIV. San Diego, 666 s.

Baytop, T., 1994. Türkiye Bitki Adları Sözlüğü. Atatürk Kültür Dil ve Tarih Kurumu Yayın No: 578. Ankara, $512 \mathrm{~s}$.

Baytop, T., 1999. Türkiye'de Bitkilerle Tedavi; Geçmişte ve Bugün. Nobel Tıp Kitabevleri. İstanbul, $480 \mathrm{~s}$.

Bektaş, E., Cüce, M., Sökmen, A., 2013. In vitro germination, protocorm formation, and plantlet development of Orchis coriophora (Orchidaceae), a naturally growing orchid species in Turkey. Turkish Journal of Botany, 37: 336-342. doi:10.3906/bot1205-28

Blinova, I.V., Uotila, P., 2012. Dactylorhiza traunsteineri (Orchidaceae) in murmanks region (Russia). Memoranda Societatis pro Fauna et Flora Fennica, 88:

67-79. https://journal.fi/msff/article/view/7819

Çalışkan, Ö., 2018. Salep Orkideleri. Erol Ofset. Samsun, $105 \mathrm{~s}$.

Çağlayan, K., Özavcı, A., Eskalen, A., 1998. Doğu Akdeniz bölgesinde yaygın olarak yetișen bazı salep orkidelerinin embriyo kültürü kullanılarak in vitro koşullarda çoğaltılmaları. Turkish Journal of Agriculture and Forestry, 22: 187-191.

Çı̆̆, A., Demirer Durak, E., İşler, S., 2018. In vitro symbiotic germination potentials of some Anacamptis, Dactylorhiza, Orchis and Ophrys terrestrial orchid species. Applied Ecology and Environmental Research, 16(4): 5141-5155. 10.15666/aeer/1604_51415155

Daşkın, R., Yılmaz, Ö., Kaynak, G., 2007. A new record for the flora of Turkey: Dactylorhiza maculata (L.) Soó (Orchidaceae). Journal of Biological and Environmental Sciences, 1(1): 1114.

Ernaz, E.A., Sevgi, E., Kara, Ö., Sevgi, O., Tecimen, H.B., Bolat, İ., 2012. Comparative morphological, anatomical and habitat studies on Dactylorhiza romana (Seb.) Soó subsp. romana and Dactylorhiza romana (seb.) Soó subsp. georgica (Klinge) Soó ex
Renz \& Taub. (Orchidaceae) in Turkey. Pakistan Journal of Botany, 44: 143-152.

Gorbani, A., Gravendeel, B., Zarre, S., Boer, H., 2014. Illegal wild collection and international trade of cites listed terretrial orchid tubers in Iran. Traffic Bulletin, 26(2): 53-58.

Hossain, M.M., 2011. Therapeutic orchids: traditional uses and recent advances-An overview. Fitoterapia, 82: 102-140. https://doi.org/ 10.1016/j.fitote.2010.09.007

Farhoosh, R., Riazi, A., 2007. A compositional study on two currents types of salep in Iran and their reolojical properties as a function of concentration and temperature. Food Hydrocolloids, 21: 660-666. https://doi.org/10.1016/j.foodhyd.2006.07.021

Jacobsone, G., 2008. Morphogenesis of wild orchid Dactylorhiza fuchsii in tissue culture. Acta Universitatis Latviensis, 745(Biology): 17-23.

Isin, M.P., 2008. Salep, spiced winter drink and cure-all (salep, rahat-1 can sihhatü'l-ebdan talim-i nefayis). I. Uluslararası Tip Tarihi Kongresi ve 10. Ulusal Tip Tarihi Kongresi (20-24 May1s 2008, Konya) Bildirileri, 382-395.

Kasparek, M., Grim, U., 1999. Europen trade in Turkish salep with special reference to Germany. Economic Botany, 53(4): 396-406. https://doi.org/10.1007/BF02866718

Mehra, S., 2014. Nutritional and genetic diversity in orchid mycorrhizal fungi from Caladenia species. Doktora Tezi, RMIT University School of Applied Sciences, College of Science Engineering and Health, $436 \mathrm{~s}$, Melbourne.

Özkoç, İ., 1991. Serapias vomeracea (Burm.fil.) briq.subsp laxiflora (Soo) Gölz et. Reinhard ve Orchis laxiflora lam. (Orchidaceae) tohumlarının simbiyotik ve asimbiyotik kültürlerde çimlenme ve gelişmesi üzerinde araştırmalar. Doktora tezi, Ondokuz Mayıs Üniversitesi Fen Bilimleri Enstitüsü, 77 s, Samsun.

Rasmussen, H.N., 1995. Terrestrial orchids: from seed to mycotrophic plant. Cambridge University Press, 444 s, Cambridge.

Renz, J., Taubenheim, G., 1984. Orchis L. (Orchidaceae), in: (Ed.): P.H. Davis, Flora of Turkey and the East Aegean Islands. Edinburgh University Press, 8:451-600, Edinburgh.

Sezik, E., 1984. Orkidelerimiz. Sandoz Kültür Yayınları No:6, $166 \mathrm{~s}$, İstanbul.

Sezik, E., 2002. Turkish orchids and salep. Acta Pharmaceutica Tursica, 44: 151-157.

Sezik, E., İşler, S., Güler, N., Orhan, Ç., Aybeke, M., Deniz, İ.G., Üstün, O., 2007. Salep ve orkidelerin tahribi. Tübitak, TBAG-Ç.SEK/23 (103T008) no'lu proje sonuç raporu, Ankara.

Shipunov, A.B., Fay, M.F., Pillon, Y., Bateman, R.M., Chase, W., 2004. Dactylorhiza (Orchidaceae) in European, Russia: combinet moleculer and morphological analysis. American Journal of 

Botany,
91(9):
1419-1426.

https://doi.org/10.3732/ajb.91.9.1419

Tutar, M., Parlak, S., Sarı, A.O., Çiçek. F. 2013. Salep orkidelerinde tohumdan üretimi. XI. Ulusal Ekoloji ve Çevre Kongresi (1-4 Ekim 2013, Samsun) Bildirileri, 241-249.

Warghat, A.R., Bajpai, P.K., Srivastava, R.B., Chaurasia, P., Chauhan, R.S., Sood, H., 2014. In vitro protocorm development and mass multiplication of an endangered orchid, Dactylorhiza hatagirea. Turkish Journal of Botany, 38: 737-746. https://dx.doi.org/10.3906/bot-1308-48 